\title{
Time Series Observation on Phytoplankton Dynamics in the Coastal Waters of the World Heritage Site of Indian Sundarban Mangrove Forest, NE Coast of Bay of Bengal
}

\author{
Abhijit Mitra $^{1 *}$ and Kakoli Banerjee ${ }^{2}$ \\ ${ }^{1}$ Department of Marine Science, University of Calcutta, 35 B.C. Road, Kolkata, India \\ ${ }^{2}$ Department of Biodiversity \& Conservation of Natural Resources, Central University of Orissa, Landiguda, Koraput, Odisha, India
}

\begin{abstract}
Sea levels on the Indian sub-continent are increasing at the rate of about $2.5 \mathrm{~mm} / \mathrm{year}$; the rate of increment is greater in the eastern coast, with an estimated sea level rise of about $3.14 \mathrm{~mm} / \mathrm{year}$. This suggests that mean annual sea levels in the Indian sub-continent will be some $15 \mathrm{~cm}$ higher in 2060 than what it was during 2000. The Indian Sundarbans in northeast coast of the country, at the apex of the Bay of Bengal is an extremely dynamic deltaic lobe sustaining a wide spectrum of mangrove flora and fauna. It is estimated that sea level in this deltaic lobe has increased by about $15 \mathrm{~cm}$ since the 1950s and this has been correlated with changes in the pattern and rates of erosion and accretion in the islands of the Indian Sundarbans. Such geo-physical phenomena may not only pose serious impact on the adjacent aquatic system by way of increasing turbidity, nutrient budget, salinity, pH etc., but the phenomenon has every possibility to shift the biodiversity spectrum of the adjacent land masses (supporting mangrove and mangrove associate species) and aquatic system due to salinization of land, alteration of soil $\mathrm{pH}$, increased erosional activities leading to reduction of water transparency, increased salinity of the water bodies and invasion of the areas with more number of stenohaline species (preferably phytoplankton). The present paper is an attempt to scan the time series observation on phytoplankton dynamics in the coastal waters of Indian Sundarban mangrove forest, NE coast of Bay of Bengal. Twenty four stations have been selected in the present programme at different salinity gradients to evaluate the temporal variations of selective hydrological parameters like surface water temperature, salinity, $\mathrm{pH}$, dissolved oxygen, transparency and nutrient load. Simultaneous data on phytoplankton diversity was also assessed to critically analyze the impact of temporal oscillation of hydrological parameters on the tiny, free floating, drifting, primary producer community. Duncan test applied on the data set of 25 years (1990 to 2015) revealed significant temporal variations of surface water temperature, salinity, $\mathrm{pH}$, transparency, nitrate concentration, phosphate concentration and phytoplankton composition. Since 1990, nine stenohaline phytoplankton species have been recorded in the upstream regions of the deltaic lobe indicating a gradual shifting of aquatic phase towards high salinity. Few environmental variables like dissolved oxygen and silicate did not show variations at significant level. Although the time span is too short to predict potential impact of aquatic climate change on phytoplankton community of the mangrove dominated Indian Sundarbans, but significant temporal variation in the phytoplankton community since 1990 speaks in favour of using these tiny, free floating, drifting, primary producer community as potential bioindicators of aquatic climate change in short term scale.
\end{abstract}

Keywords: Morphometric variation; Length of weight; Mangrove

\section{Introduction}

The climate of the earth has never been static. It is highly dynamic and continuously changing with respect to time. The climatic condition of the cretaceous period was very much different from what it is now; it was even different from what it was 10,000 years ago, when large ice sheets used to cover the high latitudes of the northern hemisphere. The pulse of climate change can be best witnessed in the domain of biological diversity e.g., during cretaceous period, dinosaurs dominated the life on earth and tropical plants thrived at high latitudes. The biological spectrum existing today in the global landscape has minimum similarity with that existing 20,000 or 30,000 years back in a different set of climatic condition. The phenomenon of climate change may be partly attributed to natural causes such as fluctuations in the earth's orbit around the sun and partly contributed by anthropogenic factors like industrialization and urbanization. The later factor has generated carbon dioxide, methane, nitrous oxide, CFCs, atmospheric particles (aerosols) etc. Observations of Berger A and Loutre MF [1] depict that if the greenhouse gas concentration increases next 50 years or so at the current rate, the climate may well be modified for more than $1,00,000$ years in future.

The climate system of the planet Earth is thus a function of natural, internal processes and alters in response to variations in external forcing factors including solar activity, volcanic emissions, variations in the earth's orbit (orbital forcing) and greenhouse gases mainly of anthropogenic origin.

The detailed causes of the recent climate change associated with sudden cyclonic depressions, super cyclone, cider etc. are active field of research, but the scientific consensus relates increased levels of greenhouse gases to anthropogenic activities. This attribution is confirmed from the most recent history of 50 years, for which detailed data are available. Contrasting with the scientific consensus, other

*Corresponding author: Mitra A, Department of Marine Science, University of Calcutta, 35 B.C. Road, Kolkata 700019, India, Tel: +965-99179176; E-mail: kamaruddineddiwan@gmail.com

Received February 12, 2018; Accepted March 20, 2018; Published March 28, 2018

Citation: Mitra A, Banerjee K (2018) Time Series Observation on Phytoplankton Dynamics in the Coastal Waters of the World Heritage Site of Indian Sundarban Mangrove Forest, NE Coast of Bay of Bengal. J Coast Zone Manag 21: 456. doi: 10.4172/2473-3350.1000456

Copyright: @ 2018 Mitra A, et al. This is an open-access article distributed under the terms of the Creative Commons Attribution License, which permits unrestricted use, distribution, and reproduction in any medium, provided the original author and source are credited. 
hypotheses have been proposed to explain most of the observed increase in global temperatures. One such hypothesis is that the warming is caused by natural fluctuations in the climate or that warming is mainly a result of variations in solar radiation [2]. None of the effects of forcing are instantaneous. Due to the thermal inertia of the Earth's oceans and slow responses of other indirect effects, the Earth's current climate is not in equilibrium with the forcing imposed. Climate commitment studies indicate that even if greenhouse gases were stabilized at present day levels, a further warming of about $0.5^{\circ} \mathrm{C}\left(0.9^{\circ} \mathrm{F}\right)$ would still occur [3-5].

The phenomenon of climate change is best expressed through rising trends of global temperature and atmospheric carbon dioxide (Figures 1 and 2).

Human activities currently release around $7-8 \mathrm{Gt}$ (Gigatonne $=10^{12}$ $\mathrm{kg}$ ) of carbon per year, compared with annual atmospheric accumulation of around $3.5 \mathrm{Gt}$ and a net oceanic absorption estimated to be between 1-3 Gt per year. Whilst independent estimates of the magnitude of terrestrial carbon sink are also needed, improvements

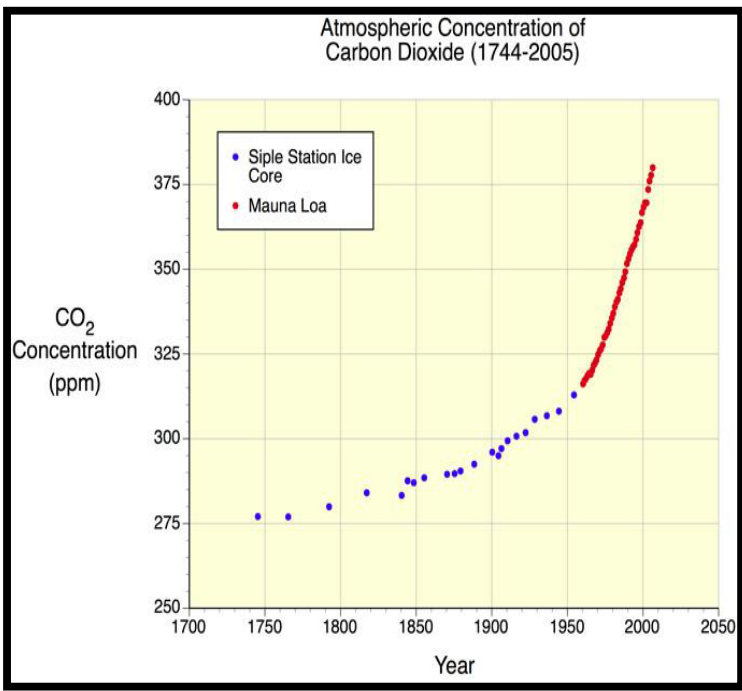

Figure 1: The graph illustrates the rise in atmospheric carbon dioxide from 1744 to 2005 . Noteworthy is the exponential increase in the atmospheric carbon dioxide's concentration.

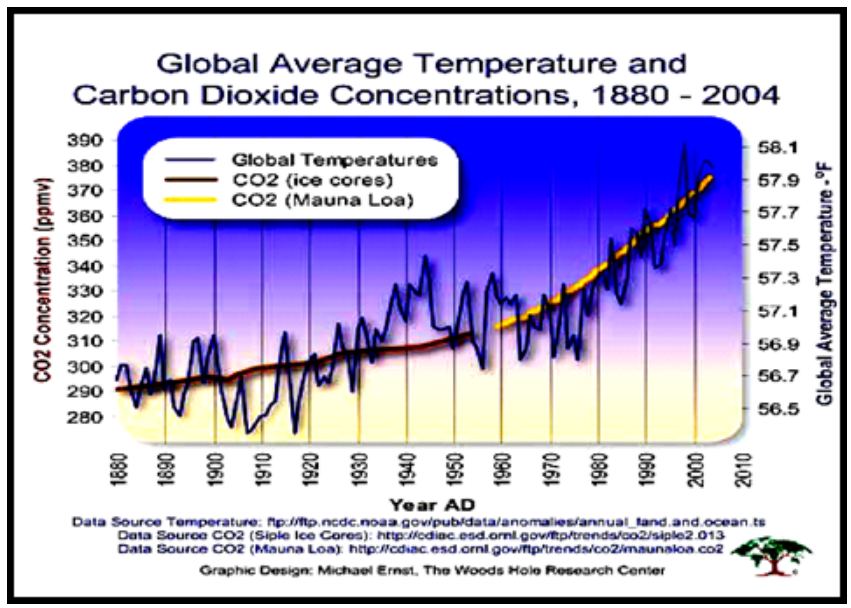

Figure 2: Mean global temperature changes since 1880. in the accuracy of the marine uptake currently offer the best approach to determine the fate of man-made $\mathrm{CO}_{2}$ emissions. This is because seawater has a unique affinity for $\mathrm{CO}_{2}$. Unlike most other gases in the atmosphere, $\mathrm{CO}_{2}$ not only dissolves in the ocean, but also reacts with its chemical constituents. As a result, nearly all the extra $\mathrm{CO}_{2}$ released into the atmosphere by human activities will eventually be absorbed beneath the waves. The phytoplankton present in the photic layer of the ocean is important biological sinks of $\mathrm{CO}_{2}$. Whilst the total net primary production on land and in the sea is similar in magnitude, the plant biomass in the oceans (mostly by phytoplankton) is around a hundred times less than on land, with its distribution and abundance much more closely matched to local and short term variability in the physical environment. The elemental composition of phytoplankton is C:N:P=106:16:1, which is commonly referred to as "Redfield Ratio". The ratio clearly explains that about 100 units of carbon are delivered to the deep sea for every 16 units of nitrogen and 1 unit of phosphorus. As such, the biological pump delivers carbon from the atmosphere to the deep sea compartment, where it is concentrated and sequestered for centuries. Several workers have found that a given population of phytoplankton can double its number in the order of once per day. In other words, phytoplankton responds very rapidly to changes in the ambient environment, which has made this community a subject of research in connection to climate change. Phytoplankton's form the foundation stone of fishery and also constitute the major diet of filter feeding molluscs. Thus any change in the phytoplankton community in response to physico-chemical variables of the ambient aquatic phase may likely to extend the impact on the nekton and benthic molluscan community. With this background, a programme to monitor the impact of aquatic climate change on the phytoplankton community of the mangrove dominated Indian Sundarbans was initiated through a collaborative project of Nature Environment \& Wildlife Society (NEWS) and Department of Marine Science, University of Calcutta, with the financial assistance of the British Deputy High Commission, Kolkata.

\section{Why phytoplankton is used as proxy?}

The study has special significance because of the following reasons:

- Phytoplankon are the major sink of atmospheric $\mathrm{CO}_{2}$. Phyto biomass in the world's ocean amount to only approximately $1-2 \%$ of the global plant carbon, yet the community fixes between $30-50$ billion metric tons of carbon annually, which is about $40 \%$ of the total.

- Phytoplankton constitutes the foundation of marine and estuarine food webs; hence any change in this community may likely to be reflected on the members of higher trophic level.

- Phytoplankton may be an important component of CDM because of their efficiency in absorption of nutrients.

- Phytoplankton standing stock and biomass variation can be easily detected through satellite imageries (owing to the presence of chlorophyll $a$ ); hence impact of climate change can be scanned over a large space.

- Blooming of phytoplankton play a large role in climate control due to the production of dimethyl sulphide, carbamyl sulphide and isoprene that produce aerosol particles when exposed to oxygen in the atmosphere. These aerosol particles in turn are responsible for the formation of low lying clouds that reflects sun's rays, mitigating global warming [4].

- The present geographical locale is one of the most 
Citation: Mitra A, Banerjee K (2018) Time Series Observation on Phytoplankton Dynamics in the Coastal Waters of the World Heritage Site of Indian Sundarban Mangrove Forest, NE Coast of Bay of Bengal. J Coast Zone Manag 21: 456. doi: 10.4172/2473-3350.1000456

biologically productive, taxonomically diverse and aesthetically celebrated ecosystems of the Indian sub-continent with three crowns of recognition (World Heritage site, Biosphere Reserve and Ramsar Site, under consideration). The implications of climate change have yet to be interpreted in terms of the Indian Sundarbans development and management and are therefore yet to be incorporated into planning decisions.

- The climate of Sundarbans is changing and this change is consistent with climate changes that are occurring throughout the world. There is an expectation that the frequency of tropical storms will decease but the intensity will increase.

- Sea levels on the Indian sub-continent are increasing at the rate of about $2.5 \mathrm{~mm}$ /year; the increase is greater in the eastern coast, with an estimated sea level rise of about $3.14 \mathrm{~mm} /$ year. The suggests that mean annual sea levels in the Indian sub-continent will be some $15 \mathrm{~cm}$ higher in 2060 than what it was during 2000. It is estimated that sea level in the Indian Sundarbans has increased by about $15 \mathrm{~cm}$ since the 1950s and this has been correlated with changes in the pattern and rates of erosion and accretion in the islands of the Indian Sundarbans. Such geo-physical phenomena may not only pose serious impact on the adjacent aquatic system by way of increasing turbidity, nutrient budget, salinity, $\mathrm{pH}$ etc., but damage on the local economics will be an important issue.

- Phytoplankton community in the present system is intricately related to mangrove forests for nutrient supply, and therefore such unique network of macro- and micro- vegetation spun through long evolutionary period of time need not be constructed (with huge expenditure and planning) to combat the effect of climate change.

\section{Materials and Methods}

The entire network of the present programme consists of the monthly sampling of water for assessing the hydrological parameters (viz. surface water temperature, salinity, $\mathrm{pH}$, dissolved oxygen, transparency and nutrient load) as per the standard protocols stated in Strickland and Parsons and enumeration of phytoplankton taxonomic diversity (through microscope fitted with an image analyzer) at 24 stations (Figure 3) in and around Sundarbans Biosphere Reserve over a period of 25 years (1990-2015).

The data presented in the present article with respect to every variable is the mean of 24 stations and 12 months of each year. This is done to normalize the local scale effect and give our effort a regional view. Year-wise data of every variable was finally subjected to Duncan test at $5 \%$ level of significance to assess the temporal variation over a span of 25 years.

\section{Results and Discussion}

Phytoplankton's are regarded as the most important producers in the marine and estuarine environment. They play the key roles in removing $\mathrm{CO}_{2}$ from the atmosphere and transferring the carbon to other trophic levels. Phytoplankton also provides a vital link to deep ocean organisms when they die and organic materials fall to the seabed. They are widely distributed in the top layer, where they receive enough solar radiation along with nutrients that are transported either by upwelling from the deep sea layer or by out welling from the adjacent landmasses. In the present geographical locale, the litters and detritus of mangrove vegetation are the major contributors of nutrients (Figure $4)$.

In addition sewage from the highly urbanized city of Kolkata also

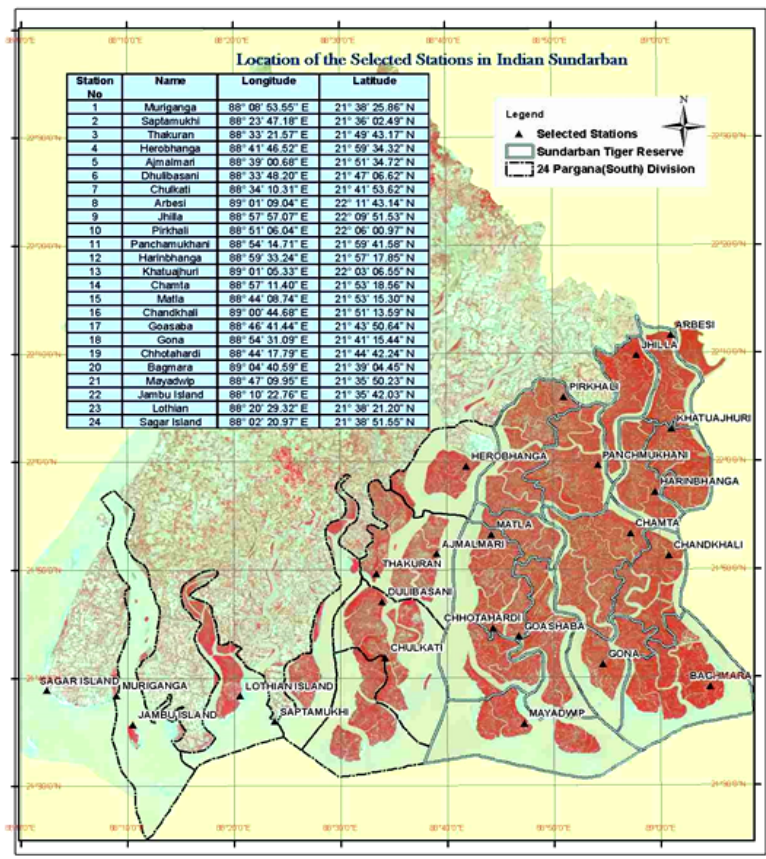

Figure 3: Location of 24 sampling stations in around Sundarbans biosphere reserve.

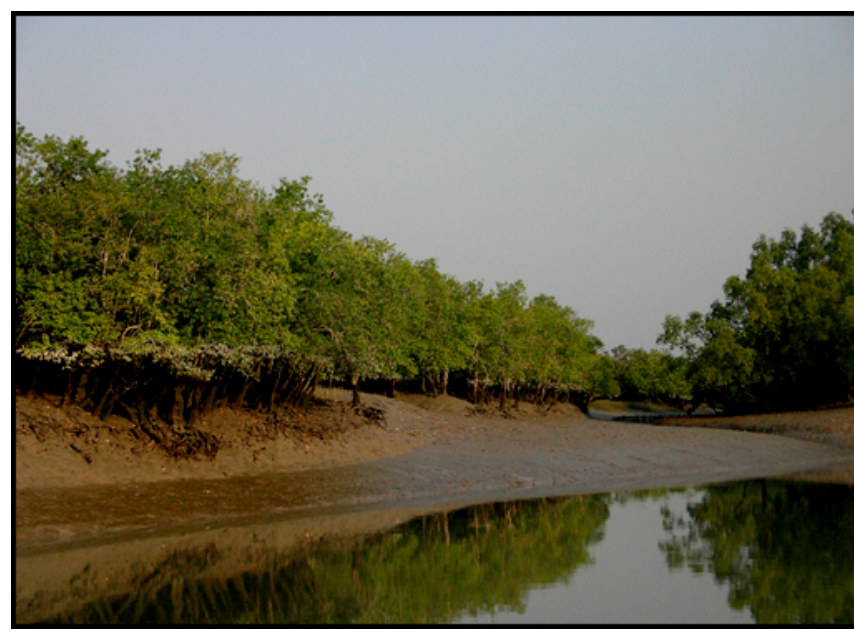

Figure 4: Mangrove vegetation in Indian Sundarbans: A rich source of nutrients for the growth and survival of phytoplankton

contain appreciable load of nitrate and phosphate that are the building blocks of phytoplankton biomass. Our knowledge of the impacts of climate change on phytoplankton populations is poor due to lack of time series data, but Duncan analysis performed on phytoplankton species diversity since 1990 showed significant variation with time. The number of phytoplankton species, increased in the aquatic sub-system of Indian Sundarbans, due to influx of few stenohaline species - an indication of gradual increase of salinity over time. The water samples collected from the upper stretch of the study area during 1990 onward having a mean salinity around 10 psu exhibited the abundance of Bacteriastrum comosum, Coscinodiscus concinnus, Asterionella formosa, Cymbella marina, Dityllum brightwelli, Triceratium pentacrinus, Fragillaria oceanica, Hemidiscus cuneformis, and Pleurosigma salinarum. 
Such findings confirm the alteration of aquatic salinity in the present geographical locale, which has been revealed through Duncan test [6$10]$.

In the initial stage the present programme generated few core findings:

- Surface water temperature in the mangrove dominated deltaic complex of Indian Sundarbans exhibited a gradual increase as revealed from Duncan test (Table 1). The change has been revealed since 1995 and in the year 2005, the temperature alteration has become significantly prominent. The rapid industrialization and urbanization of the city of Kolkata, Howrah and the newly emerging Haldia complex along with the mushrooming of brick kilns in areas like Kakdwip, Haroa, and adjacent zone of Kulti lock gate may be few possible reasons behind increased of ambient air temperature, which has been reflected on the surface water.

- Salinity of the territorial waters of Indian Sundarbans has exhibited considerable variation over a span of 25 years (Table 2 ). The change has become very prominent at an interval of every five years. Whether this is due to heavy siltation, decreased fresh water supply through Hooghly estuary, tectonic tilt of the Bengal basin towards eastward direction, or ingression of seawater from Bay of Bengal (due to sea level rise) is still to be determined.

- Surface water $\mathrm{pH}$ has shown considerable variation, which may be attributed to climate change. The decreasing trend may be correlated to more absorption of atmospheric $\mathrm{CO}_{2}$ and increased rate of sewage discharge (Table 3). The aquatic $\mathrm{pH}$ of 2005 exhibited considerable difference with those of eighties and nineties.

- Dissolved oxygen did not exhibit any marked variations over time (Table 4).

- Transparency of the aquatic phase has reduced due to increased

\begin{tabular}{|c|c|c|c|c|}
\hline \multirow[t]{2}{*}{ Year } & \multirow[t]{2}{*}{$\mathbf{N}^{*}$} & \multicolumn{3}{|c|}{ Subset for alpha $=0.05$} \\
\hline & & 1 & 2 & 3 \\
\hline 1990 & 3 & 31.0000 & & \\
\hline 1995 & 3 & 31.0667 & & \\
\hline 2000 & 3 & 31.2667 & & \\
\hline 2005 & 3 & & 31.8667 & \\
\hline 2010 & 3 & & 31.8667 & \\
\hline 2015 & 3 & & & 32.2667 \\
\hline Sig. & & 0.127 & 1.000 & 1.000 \\
\hline \multicolumn{5}{|c|}{$\begin{array}{c}\text { Means for groups in homogeneous subsets are displayed. *Uses Harmoni } \\
\text { Mean Sample Size }=3.000\end{array}$} \\
\hline
\end{tabular}

Table 1: Variation of surface water temperature over a period of 25 years.

\begin{tabular}{|c|c|c|c|c|c|c|}
\hline \multirow{2}{*}{ Year } & \multirow{2}{*}{$\mathbf{N}^{*}$} & \multicolumn{5}{|c|}{ Subset for alpha=0.05 } \\
\cline { 3 - 7 } & & 1 & 2 & 3 & 4 & 5 \\
\hline 1990 & 3 & 12.3000 & & & & \\
\hline 1995 & 3 & & 12.9400 & & & \\
\hline 2000 & 3 & & 13.2333 & & & \\
\hline 2005 & 3 & & & 14.1667 & & \\
\hline 2010 & 3 & & & & 15.1000 & \\
\hline 2015 & 3 & & & & & 16.4333 \\
\hline Sig. & & 1.000 & 0.312 & 1.000 & 1.000 & 1.000 \\
\hline
\end{tabular}

Means for groups in homogeneous subsets are displayed. *Uses Harmonic Mean Sample Size $=3.000$

Table 2: Variation of surface water salinity over a period of 25 years.

\begin{tabular}{|c|c|c|c|c|c|}
\hline Year & $\mathbf{N}^{*}$ & \multicolumn{4}{|c|}{ Subset for alpha=0.05 } \\
\hline & & 1 & 2 & 3 & 4 \\
\hline 1990 & 3 & 8.2200 & & & \\
\hline 1995 & 3 & & 8.2533 & & \\
\hline 2000 & 3 & & & 8.2900 & \\
\hline 2005 & 3 & & & & 8.3167 \\
\hline 2010 & 3 & & & & 8.3200 \\
\hline 2015 & 3 & & & & 8.3233 \\
\hline Sig. & & 1.000 & 1.000 & 1.000 & .360 \\
\hline
\end{tabular}

Means for groups in homogeneous subsets are displayed. *Uses Harmonic Mean Sample Size $=3.000$

Table 3: Variation of surface water $\mathrm{pH}$ over a period of 25 years.

\begin{tabular}{|c|c|c|}
\hline Year & $\mathbf{N}^{*}$ & Subset for alpha=0.05 \\
\hline & & 1 \\
\hline 1990 & 3 & 5.0233 \\
\hline 2000 & 3 & 5.0533 \\
\hline 2005 & 3 & 5.0533 \\
\hline 2010 & 3 & 5.0600 \\
\hline 2015 & 3 & 5.0700 \\
\hline Sig. & 3 & 5.0733 \\
\hline
\end{tabular}

Means for groups in homogeneous subsets are displayed. *Uses Harmonic Mean Sample Size $=3.000$

Table 4: Variation of dissolved oxygen over a period of 25 years.

\begin{tabular}{|c|c|c|c|c|c|c|}
\hline \multirow{2}{*}{ Year } & \multirow{2}{*}{$\mathbf{N}^{*}$} & \multicolumn{5}{|c|}{ Subset for alpha=0.05 } \\
\hline & & 1 & 2 & 3 & 4 & 5 \\
\hline 1990 & 3 & 20.3667 & & & & \\
\hline 1995 & 3 & & 22.0667 & & & \\
\hline 2000 & 3 & & & 24.9667 & & \\
\hline 2005 & 3 & & & 25.4000 & 25.4000 & \\
\hline 2010 & 3 & & & & 25.9333 & \\
\hline 2015 & 3 & & & & & 26.8333 \\
\hline Sig. & & 1.000 & 1.000 & 0.153 & 0.085 & 1.000 \\
\hline
\end{tabular}

Means for groups in homogeneous subsets are displayed. *Uses Harmonic Mean Sample Size $=3.000$

Table 5: Variation of water transparency over a period of 25 years.

erosion of the adjacent landmasses (Table 5), may be a direct consequence of sea level rise and subsequent tidal amplitude.

- The nutrient load has increased with the passage of time (except silicate), which may be due to hike up in the sewage discharge from the adjacent cities, towns and villages or unplanned mushrooming of shrimp farms in and around the Sundarbans Biosphere Reserve (that generate nitrate, phosphate etc.). The erosion of the adjacent landmasses and mangrove forests are also the major contributors of nutrients (Tables 6-8).

- Phytoplankton species diversity exhibited significant variation since 1990, with more numbers of stenohaline species (Table 9) in the upstream areas.

\section{Conclusion}

The islands of Indian Sundarbans, at the apex of the Bay of Bengal 
Citation: Mitra A, Banerjee K (2018) Time Series Observation on Phytoplankton Dynamics in the Coastal Waters of the World Heritage Site of Indian Sundarban Mangrove Forest, NE Coast of Bay of Bengal. J Coast Zone Manag 21: 456. doi: 10.4172/2473-3350.1000456

Page 5 of 5

\begin{tabular}{|l|c|c|c|c|c|c|}
\hline \multirow{2}{*}{ Year } & \multirow{2}{*}{$\mathbf{N}^{*}$} & \multicolumn{5}{|c|}{ Subset for alpha =0.05 } \\
\hline & & $\mathbf{1}$ & $\mathbf{2}$ & $\mathbf{3}$ & $\mathbf{4}$ & $\mathbf{5}$ \\
\hline 1990 & 3 & 19.0367 & & & & \\
\hline 1995 & 3 & 19.3333 & 19.3333 & & & \\
\hline 2000 & 3 & & 19.9667 & & & \\
\hline 2005 & 3 & & & 21.9333 & & \\
\hline 2010 & 3 & & & & 22.7667 & \\
\hline 2015 & 3 & & & & & 24.2667 \\
\hline Sig. & \multicolumn{7}{|c|}{0.432} & 0.108 & 1.000 & 1.000 & 1.000 \\
\hline Means for groups in homogeneous subsets are displayed. *Uses Harmonic \\
Mean Sample Size=3.000 \\
\hline
\end{tabular}

Table 6: Variation of nitrate over a period of 25 years.

\begin{tabular}{|c|c|c|c|c|c|c|}
\hline \multirow{2}{*}{ Year } & \multirow{2}{*}{$\mathbf{N}^{*}$} & \multicolumn{5}{|c|}{ Subset for alpha = 0.05 } \\
\cline { 3 - 7 } & & $\mathbf{1}$ & $\mathbf{2}$ & $\mathbf{3}$ & $\mathbf{4}$ & $\mathbf{5}$ \\
\hline 1990 & 3 & 1.9133 & & & & \\
\hline 1995 & 3 & 1.9800 & 1.9800 & & & \\
\hline 2000 & 3 & & 2.1167 & & & \\
\hline 2005 & 3 & & & 2.3933 & & \\
\hline 2010 & 3 & & & & 2.6400 & \\
\hline 2015 & 3 & & & & & 2.9100 \\
\hline Sig. & & 0.432 & 0.121 & 1.000 & 1.000 & 1.000 \\
\hline
\end{tabular}

Means for groups in homogeneous subsets are displayed. *Uses Harmonic Mean Sample Size $=3.000$

Table 7: Variation of phosphate over a period of 25 years.

\begin{tabular}{|c|c|c|}
\hline Year & $\mathbf{N}^{\mathbf{*}}$ & Subset for alpha=0.05 \\
\hline 1990 & & 1 \\
\hline 1995 & 3 & 95.8100 \\
\hline 2000 & 3 & 96.4333 \\
\hline 2005 & 3 & 96.6633 \\
\hline 2010 & 3 & 96.8100 \\
\hline 2015 & 3 & 96.9300 \\
\hline Sig. & & 99.5533 \\
\hline Means for groups in homogeneous subsets are displayed. * Uses Harmonic \\
\multicolumn{2}{|c|}{ Mean Sample Size =3.000 } \\
\hline \multicolumn{2}{|c|}{} \\
\hline
\end{tabular}

Table 8: Variation of silicate over a period of 25 years.

\begin{tabular}{|c|c|c|c|}
\hline Year & N & \multicolumn{2}{|c|}{ Subset for alpha=0.05 } \\
\hline & & 1 & 2 \\
\hline 1990 & 3 & 87.3333 & \\
\hline 1995 & 3 & 88.6667 & \\
\hline 2000 & 3 & & 98.6667 \\
\hline 2005 & 3 & & 100.0000 \\
\hline 2010 & 3 & & 100.6667 \\
\hline 2015 & 3 & 0.356 & 101.0000 \\
\hline Sig. & & & 0.145 \\
\hline Means for groups in homogeneous subsets are displayed. * Uses Harmonic \\
\hline \multicolumn{2}{|c|}{ Mean Sample Size=3.000 } \\
\hline
\end{tabular}

Table 9: Variation of phytoplankton over a period of 25 years.

form a heterogeneous group with respect to salinity. The upper stretch of the deltaic complex in the Hooghly estuarine stretch is a low saline zone, where surface water used to touch zero in the monsoon period during early eighties. Presence of stenohaline phytoplankton species in these zones in recent times is an indication of alteration of water quality. Alterations in nutrient levels and temperature may also effect the species composition of phytoplankton populations in different regions, which would have serious repercussions on the rest of the marine environment. Thus the phytoplankton community in the marine and estuarine ecosystems might be a unique vault to preserve the signature of climate change since long evolutionary period of time.

\section{References}

1. Berger A, Loutre MF (2006) From astronomical theory to global warming.

2. Leidig S, Michael R, Roya N (2004) The truth about global warming, it's the Sun that's to blame.

3. http://www.royalsoc.ac.uk/displaypagedoc.asp?id=13619

4. http://news.ncsu.edu/releases/2006/nov/194.html

5. Gerald A, Meehl A, Warren M, Washington D, Julie M, et al. (2005) Strand and Haiyan Teng. How much more global warming and sea level rise? Sci 307: 1769-1772.

6. Berg CJ (1974) A comparative ecological studiesw of strombid gastrowpods. Behavior 51: 274-321.

7. Catterall C, Poiner IR (1983) Age and dependent pattern of aggregation in the tropical gastropod Strombus luhuanus. Marine Biology 77: 171-182.

8. Berg CJ (1974) A comparative ecological studies of strombid gastrowpods Behavior 51: 274-321.

9. Bagli S, Soille P, Fermi E (2004) Automatic delineation of shoreline and lake boundaries from Landsat satellite images. Proceedings of initial Eco-Imagine GI and GIS for Integrated Coastal Management, Seville. pp: 13-15.

10. Effendie MI (1979) Method of fisheries biology. 